Bangladesh J. Bot. 41(1): 1-5, 2012 (June)

\title{
RADIOSENSITIVITY OF SOME LOCAL CULTIVARS OF WHEAT (TRITICUM AESTIVUM L.) TO GAMMA IRRADIATION
}

\author{
MMA ALBOKARI*, SM AlZAHRANi AND AS ALSALMAN \\ Atomic Energy Research Institute (AERI), King Abdulaziz City for Science and Technology \\ (KACST), P. O. Box 6086, Riyadh 11442, Saudi Arabia
}

Key words: Radiosensitivity, Gamma irradiation, Seedling height, Local cultivars, Wheat

\begin{abstract}
Seeds of four local wheat (Triticum aestivum L.) cultivars, namely Hinta, Khaliji, Lokaimy and Qasime collected from different regions of Saudi Arabia were exposed to different doses of gamma rays 50-500 Gy to determine suitable doses for induction of mutation. It was observed that seedling height decreased with the increased dose of radiation in all cultivars. Radiosensitive curve originated from seedling height data resulted in 179, 225, 249 and 256 Gys as $\mathrm{LD}_{50}$ values for the cultivars Hinta, Khaliji, Qasime and Lokaimy, respectively. Based on $\mathrm{LD}_{50}$, as to minimize DNA damage and reduce undesirable mutations, radiation doses which lie between 200 and 250 Gy can be considered suitable for induction of mutation in cultivars Lokaimy, Khaliji and Qasime while between 150 and 200 Gy for cultivar Hinta.
\end{abstract}

\section{Introduction}

Kingdom of Saudi Arabia is one of the driest countries of the world. Its harsh desert climate does not support any river or lake and thats why the crop production is fully dependent on ground water. Wheat is one of the most important crops in Saudi Arabia. The country has been considered as one of the largest suppliers for the global wheat markets and has reached self-sufficiency for local wheat landraces. But huge consumption of groundwater for irrigation has created major problems such as depletion of aquifers and deterioration of groundwater quality. The result may be adverse economic consequences coupled with negative environmental and social effects. Therefore, immediate public action is imperative to prevent or minimize the impacts of the depletion of groundwater resources (Al-Ibrahim 1991). This situation has led to a very serious rethinking of the issue and long-term sustainability of exploiting groundwater resources, in particular for use in water-intensive agricultural practices. So cultivation of wheat with its current irrigation demand is unsustainable. In this context, development of new wheat varieties with early maturity, tolerant to drought, heat and diseases having high yield potential is highly desirable.

The use of physical mutagens like X-rays, gamma rays and neutrons and chemical mutagens help to improve many traits of agronomical importance in major crops such as wheat, rice, barley, cotton and beans (Gustafsson et al. 1971, Hassan 1986, Ahloowalia and Maluszynski 2001, Maluszynski and Kasha 2002).

Radiosensitivity test is a relative measure that gives an indication of the quantity of recognizable effects of radiation on the irradiated objects (Morishita et al. 2003). This work was carried out in order to determine the lethal doses $50\left(\mathrm{LD}_{50}\right)$, which usually creates maximum variability with minimum numbers of undesirable mutants. Plants differ in radiosensitivity and low doses of gamma radiation enhanced growth in plants. In cereals, radiosensitivity is genotypic dependence. It is highly desirable to establish a radiosensitive curve and determine $L_{50}$ of mutagen for treating seeds, for the induction of mutations in cereals and others. $\mathrm{LD}_{50}$ is defined as the dose at which $50 \%$ of the irradiated objects die after irradiation and is considered as a dose at

*Author for correspondence: <mbokari@kacst.edu.sa> 
which highest frequency of mutation occurs. On the other hand, $\mathrm{LD}_{100}$ is the dose at which all the irradiated objects die.

The national program is emphasizing on developing cultivars of wheat with early maturation, drought, heat and disease tolerant characters. Therefore, determination of suitable doses of gamma irradiation for induction of mutation in local wheat cultivars is a pre-requisite that will accelerate in producing good mutant lines with desired characteristics. The present study is aimed at determining the Lethal Doses $50\left(\mathrm{LD}_{50}\right)$ and $100\left(\mathrm{LD}_{100}\right)$.

\section{Materials and Methods}

Seeds of four local summer cultivars of wheat (Triticum aestivum L.), namely Hinta, Khaliji, Lokaimy and Qasime were collected from different regions of Saudi Arabia. Treatment and irradiation of seeds with different doses of gamma rays were carried out following the methods of Kodym and Afza (2003). Healthy seeds of each cultivar were taken in air and water permeable seed envelopes and labeled them accordingly. The packed seeds of each cultivar were placed in a vacuum desiccators over glycerol $(60 \% \mathrm{v} / \mathrm{v})$ and left at room temperature for $5-7$ days in order to lower down the seed moisture content to $12-14 \%$, which is the ideal condition for achieving efficient induction of mutation.

Sixty seeds of each cultivar per treatment were exposed to 50, 100, 150, 200, 250, 300, 350, 400, 450 and 500 Gy doses of gamma rays from a Cobalt ${ }^{60}$ gamma irradiator (Gammacell Research Irradiator, Model Excell 220 manufactured by MDS Nordion, Canada). The dose rate was $7.44 \mathrm{kGy} / \mathrm{h}$ and the source was calibrated using fricke dosimeter (ASTM Standard Practice E1026, 2011).

Flat method was followed for sowing irradiated seeds. Seeds were sown after one day of irradiation in sterilized soil at the greenhouse in the Agricultural Research Station (30 km west of Riyadh). The seeds were planted in three replications and there were 20 seeds per replicate. Unirradiated parental seeds were also included in the experiment for using as control.

Three hundred unirradaited seeds of each cultivar were sown in Petri dishes with sterilized soil in order to investigate the percentage of germination with using 100 seeds in each replication.

Number of untreated seed was recorded after 20 days of placing the seeds in soil as well as in Petri dishes. Seedling height against different doses of gamma irradiation was recorded after three weeks of planting germinated seeds in the soil.

\section{Results and Discussion}

The result of seed germination is shown in Fig. 1. It was observed that cultivar Lokaimy responded $100 \%$ in soil followed by Khaliji (95\%) while Hinta and Qasime gave similar response (85\%). On the other hand, in Petri dishes Lokaimy, Khaliji and Qasime yielded identical response (90\%) followed by Hinta (80\%). So, the majority of seeds were found viable and actively germinating. However, the soil medium showed better germination response compared to Petri dishes in all cultivars except Qasime.

Per cent seedling height and seedling height reduction curve using a simple linear regression (Excel 2007) for different doses of gamma irradiation are shown in Figs 2A-D. It is revealed that $\mathrm{LD}_{50}$ values for cultivars Hinta, Lokaimy, Khaliji and Qasime were found as 179, 256, 225, and 249 Gys, respectively while $\mathrm{LD}_{100}$ values for the said cultivars in the same order were recorded as $350,400,350$ and $400 \mathrm{~Gy}$, respectively. $\mathrm{LD}_{50}$ is considered as a dose for getting highest frequency of mutation. Higher mutagen dose's treatment will cause more damage to DNA that would result in large number of undesirable mutations (Britt 1996), and their handling will be difficult for the 
isolation of desirable mutants. Lower mutagen treatments, e.g. $\mathrm{LD}_{25}$ or $\mathrm{LD}_{35}$, will minimize DNA damage and reduce in inducing large number of undesirable mutations and the chances of isolating desirable mutations will be higher.

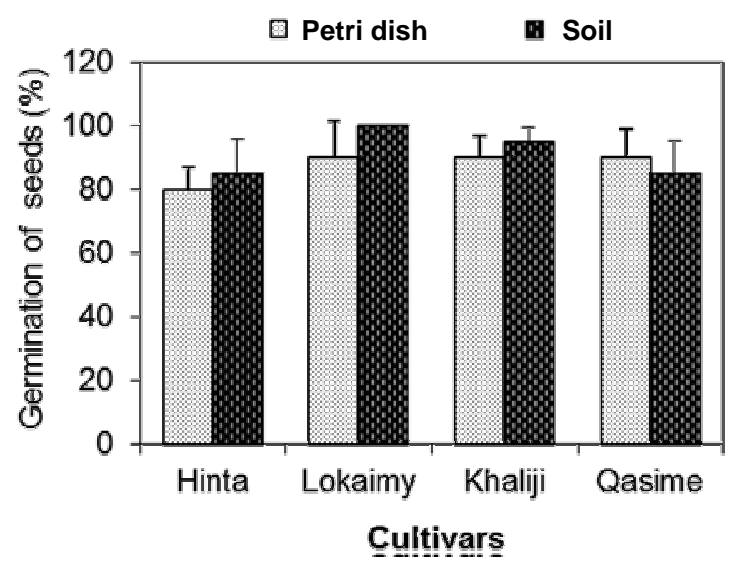

Fig.1. Histogram showing per cent germination of non-irradiated seeds of wheat cultivars in Petri dish and in sterilized soil. (Each column is a mean of three replicates and bar represents standard error).

Radiosensitivity test between $\mathrm{LD}_{30}$ and $\mathrm{LD}_{50}$ is preferable to obtain the desired and optimum traits (Millado et al. 1972, Choudhury 1983, Maluszynski et al. 2003). In the present study, $\mathrm{LD}_{30}$, $\mathrm{LD}_{50}, \mathrm{LD}_{100}$ and their corresponding irradiation dose for four wheat cultivars used revealed that radiation doses which lie between 200 and 250 Gy can be considered as suitable doses for cultivars Lokaimy, Khaliji and Qasime while between 150 and 200 Gy for cultivar Hinta (Fig. 3). These results are in agreement with the findings of Saif et al. (2004) with local tetraploid and hexaploid wheat cultivars. Radiosensitivity varies with the species and the cultivar, with the physiological condition of plant and its parts, and with the manipulation of the irradiated material before and after mutagenic treatment. Correlations between the physiological status of plants and their radiosensitivity are often correlated to water content of the tissue, since the most frequent primary target of ionizing radiation is the water molecule (Britt 1996).

Din et al. (2004) conducted radiosensitivity on five wheat genotypes irradiated with 15, 25, 35 and $45 \mathrm{kR}$ doses of gamma rays, where they observed significant decrease in plant height with the increase of doses of gamma rays in five wheat genotypes. Millado et al. (1972) studied the effect of various doses of gamma radiation on plant height, number of tiller and grain weight per plant in wheat and concluded that in general 10 and $15 \mathrm{kR}$ increased the mean value of each trait studied. On the other hand, higher doses tended to reduce them. Irfaq and Nawab (2003) observed adverse effects on the most of the parameters of wheat as a result of higher doses (300 and $400 \mathrm{~Gy}$ ). Borzouei et al. (2010) treated two wheat cultivars with different doses of gamma irradiation (100 and 400 Gy). They found that root and shoot length and dry weight of seedlings decreased with increased doses of radiation. All these results in the context of seedling height are in conformity with present findings. Borzouei et al. (2010) also observed that seedlings originated from 100 Gy dose contained highest amount of proline and higher chlorophyll content compared to non-irradiated seedlings. These results showed that the upgrading of some physiological characteristics and seedling growth of wheat following gamma radiation treatment may be used for abiotic control such as drought and salt stress. 

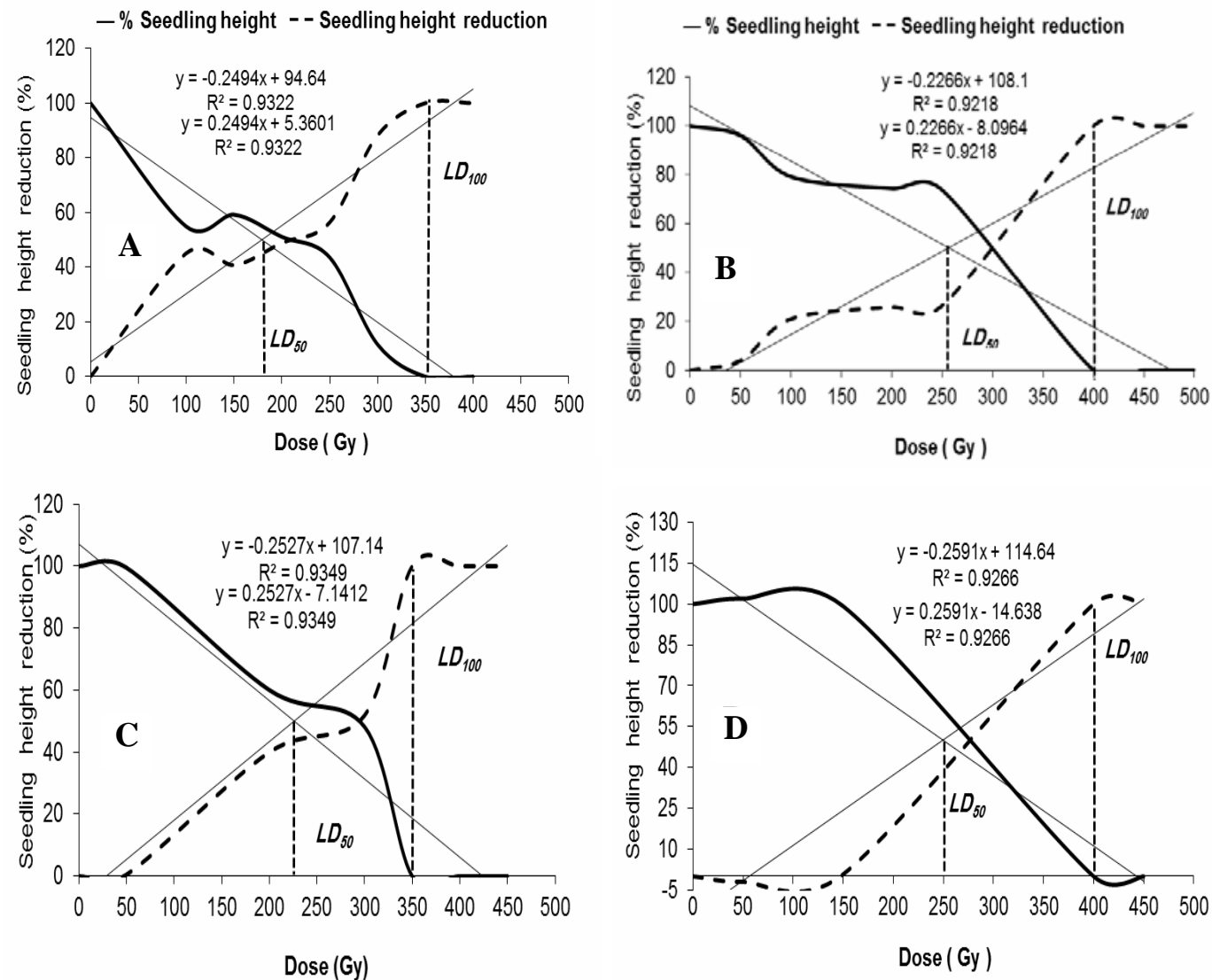

Figs 2A-D. Radiosensitive curves for $\mathrm{LD}_{50}$ and $\mathrm{LD}_{100}$ of cultivars Hinta (A), Lokaimy (B), Khaliji (C) and Qasime (D).

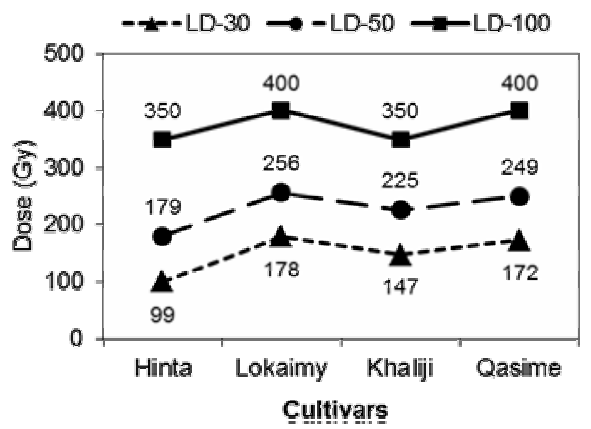

Fig. 3. Line chart showing $\mathrm{LD}_{30}, \mathrm{LD}_{50}, \mathrm{LD}_{100}$ and their corresponding irradiation dose (Gy) for wheat cultivars.

Induced mutations are necessary to enhance the rate of genetic variability. The major advantage in induced mutations is that multiple trait mutants can be isolated. A specific advantage of mutation induction is to develop a range of mutant lines, and identify trait specific genes in order to set up molecular gene database, study molecular functional genomics and develop bio- 
informatics for future to develop plant variety to grow the existing arable land under climate change to feed rapid human population growth.

\section{Acknowledgement}

The authors wish to acknowledge King Abdulaziz City for Science and Technology (KACST) for providing financial support (Grant No. 31- 493) to carry out this research work.

\section{References}

Ahloowalia BS and M Maluszynski 2001. Induced mutations - a new paradigm in plant. Euphytica 118(2): 167-173.

Al-Ibrahim AA 1991. Excessive use of groundwater resources in Saudi Arabia: Impacts and policy options. Ambio 20(1): 34-37.

Borzouei A, M Kafi, H Khazaei, B Naseriyan and A Majdabdi 2010. Effects of gamma radiation on germination and physiological aspects of wheat (Triticum aestivum L.) seedlings. Pak. J. Bot. 42(4): 2281-2290.

Britt AB 1996. DNA-damage and repair in plants. Ann. Rev. Plant Physiol. Plant Mol. Biol. 47: 75-100.

Choudhury RK 1983. A note on the effect of gamma irradiation in wheat. Wheat Info. Sci. 57: 21-23.

Din R, M Qasim and K Ahmad 2004. Radiosensitivity of various wheat genotypes in $\mathrm{M}_{1}$ generation. Intl. J. Agril. Biol. 6(5): 898-900.

Gustafsson A, A Hagberg, G Persson and K Wikland 1971. Induced mutation and barley improvement. Theo. Appl. Genet. 41: 239-248.

Hassan S 1986. Gamma irradiation induced genetic variation in genetic parameters of wheat and triticale. Sarhad J. Agric. 2: 173-179.

Irfaq $\mathrm{M}$ and $\mathrm{K}$ Nawab 2003. A study to determine the proper dose of gamma irradiation for inducing beneficial genetic variability in bread wheat (Triticum aestivum L.). Asian J. Plant Sci. 2(13): 999-1003.

Kodym A and R Afza 2003. Physical and Chemical Mutagenesis. In: Plant Functional Genomics, Erich Grotewold (Ed.), pp. 189-204. Humana Press.

Maluszynski M and KJ Kasha (Eds.) 2002. Mutations, In vitro and Molecular Techniques for Environmentally Sustainable Crop Improvement. Kluwer Academic Publishers, Dordrecht/Boston/ London. ISBN 1-4020-0602-0.

Maluszynski M, I Szarejko and J Maluszynski 2003. Mutation techniques. In: Encyclopedia of Applied Plant Sciences,Thomas, B., D.J. Murphy and B.G. Murray (Eds.), pp. 186-201, Elsevier Academic Press, San Diego.

Millado Z, MA Trajilo and FR Mendozoz 1972. Effect of different doses of gamma rays $\mathrm{Co}^{60}$ on four quantitative characters in wheat (T. aestivum L.). Agro. Sci. 8B: 41-65.

Morishita T, H Yamaguchi, K Degi, N Shikazono, A Tanaka and T Abe 2003. Dose response and mutation induction by ion beam irradiation in buckwheat. Nucl. Instr. Meth. Phys. Res. B. 206: 565-569.

Saif AA, AA Malek, NM Zaid, AH Kaid and A Almaktari 2004. Study of radiosensitivity to gamma irradiation for some important crops in Yemen. Arab J. Nucl. Sci. \& Appl. 37(3): 279-285.

(Manuscript received on 17 September, 2011; revised on 4 February, 2012) 